\title{
Trials and tribulations in the removal of dextropropoxyphene from the Australian Register of Therapeutic Goods
}

Nick A Buckley MD, FRACP, Professor

Thomas A Faunce BA/LLB(Hons), BMed, PhD Professor $^{2}$

1 Medical Professorial Unit,

Prince of Wales Hospital Clinical School,

Sydney, NSW.

2 College of Medicine Biology and Environment and ANU College of Law

Australian National

University,
Canberra, ACT.

n.buckley@unsw.edu.au

doi: 10.5694/mjal3.10040 n November 2011, the delegate of the Secretary of the Department of Health and Ageing gave notice that the Therapeutic Goods Administration (TGA) intended to remove dextropropoxyphene (brand names Di-Gesic and Doloxene) from the Australian Register of Therapeutic Goods. ${ }^{1}$

This followed a review of the safety and efficacy of medicines containing dextropropoxyphene. The TGA "determined that the overall risk of serious adverse reactions outweighs any benefits that may be provided by these medicines". ${ }^{2}$ The main concern was the risk of sudden death from cardiotoxicity (not shared by other opioid drugs), in the setting of renal impairment, drug interactions and accidental or deliberate overdose..$^{2-6}$

Evidence against dextropropoxyphene has been accumulating for over 30 years. ${ }^{3}$ The drug has been removed from the market by medicine regulators in the United Kingdom (2004), European Union (2009), United States (2010), New Zealand (2010) and elsewhere. ${ }^{2}$ Over a decade ago, the Australian Pharmaceutical Benefits Advisory Committee (PBAC) recommended removal of subsidies for dextropropoxyphene, and the Australian Medicines Handbook and Therapeutic Guidelines advised against using the drug. ${ }^{5,6}$ However, dextropropoxyphene remains on the market in Australia in 2013, 18 months after the TGA's decision to delist it, owing to a series of legal appeals by the drug's manufacturer before the Administrative Appeals Tribunal (AAT). ${ }^{1}$

\section{Deregistration of dextropropoxyphene in the AAT}

The manufacturer of dextropropoxyphene in Australia, Aspen Pharmacare Australia Pty Ltd (Aspen), asked the Minister for Health and Ageing to reconsider the deregistration decision, but in January 2012 it was reaffirmed. The manufacturer then appealed that decision to the AAT. Both the manufacturer and the TGA accepted that the ultimate issue in the appeal was whether the "quality, safety or efficacy" of each drug "is unacceptable" within the meaning of section 30(2)(a) of the Therapeutic Goods Act 1989 (Cwlth) (the TG Act).

The AAT appeal was heard by Justice Kerr, President of the Tribunal, and Senior Member Dr Teresa Nicoletti. Teresa Nicoletti is also a partner at Piper Alderman, Founding Director of Pharmedica Consulting and a consultant to, and former regulatory and medical affairs manager with, several large pharmaceutical companies. In general terms, the appeal of the manufacturer, Aspen, was based around an argument that the drug was efficacious in some patients for whom other moderate analgesics did not work and that it could be used safely provided patients did

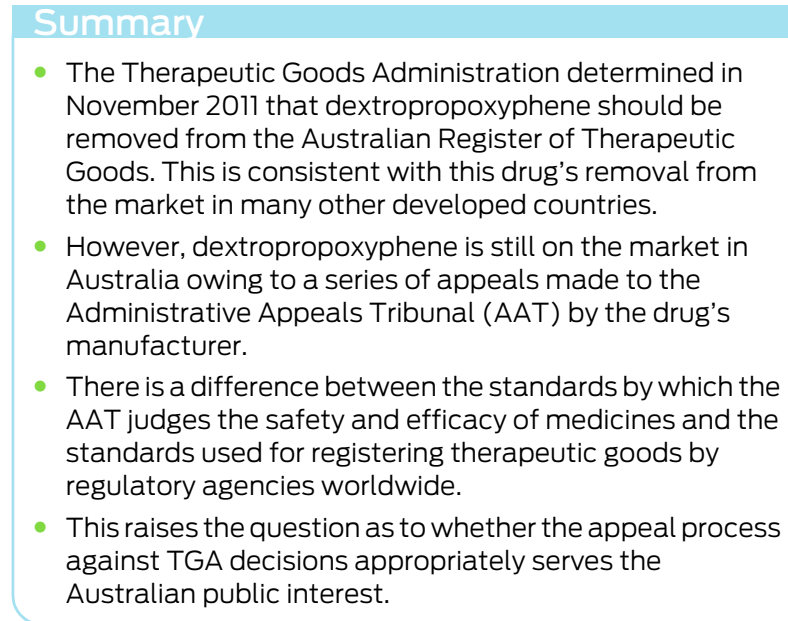

not take excessive doses, and if the prescribing indications, contraindications and warnings were all carefully observed. $^{1}$ The manufacturer also indicated [para 100] ${ }^{1}$ that it would be prepared to enter into contractual obligations with all pharmacies retailing dextropropoxyphene to supply it only on production of a signed statement from the prescribing doctor and countersigned by the patient about awareness of the risks. To obtain this stay, Aspen undertook to add significant safety warnings to the product information and consumer medicine information for Di-Gesic and Doloxene highlighting, among other things, that products containing dextropropoxyphene had recently been associated with substantial prolongation of the QT interval. Aspen also agreed to write "dear doctor" and "dear pharmacist" letters, in a form approved by the TGA, drawing attention to the additional safety warnings [para 11]. ${ }^{1}$

Evidence was tendered to the AAT that despite regulatory decisions to remove dextropropoxyphene from general availability in the UK and US, it continued to be available under prescription in those jurisdictions [para 94]. ${ }^{1}$ Rejecting arguments from the TGA's counsel that the drug be made available only under the Special Access Scheme and to authorised prescribers (s19 TG Act) (it had only remained available after the UK ban on this sort of scheme), the AAT decided to remit the matter again to the Minister to see if agreement could be reached under s28 of the TG Act for the drug to remain available with "highly visible warnings and in blister packs designed to minimise the risk of misuse" [paras 99 and 103]. ${ }^{1}$ The AAT also indicated that if the manufacturer still felt aggrieved by the TGA decision it could return to the AAT to continue its appeal. The manufacturer ultimately took up this option, and in April 2013 the AAT upheld the appeal in its final decision on this matter. ${ }^{7}$ 
Deaths from Co-proxamol* and other analgesic poisoning,

and suicide by drug poisoning, United Kingdom, 1998-2010 ${ }^{\dagger}$

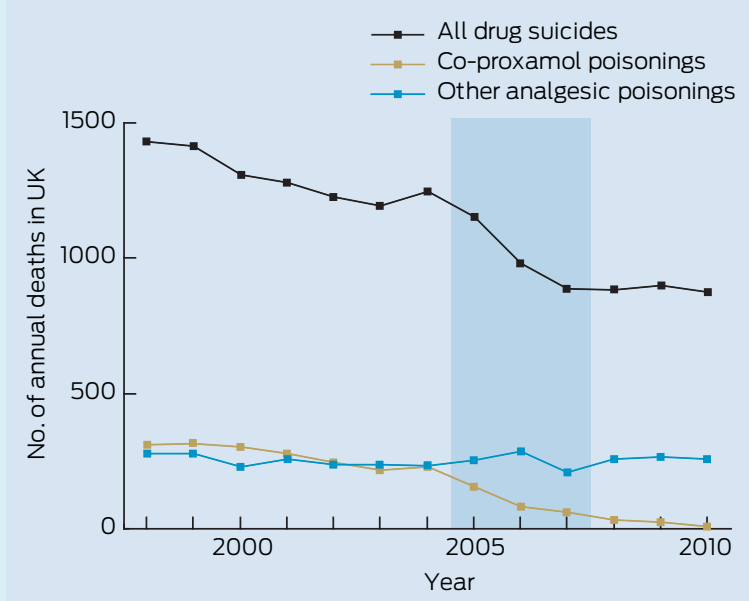

* UK brand name for dextropropoxyphene-paracetamol. † Graph drawn from data from Table 2 in: Hawton K, et al. PLOS Med 2012; 9: el001213. Shading represents the period over which a ban on dextropropoxyphene was phased in.

\section{Role of the AAT in Australian therapeutic} drug regulation

The AAT is usually the final hurdle for the TGA in regard to appeals against drug regulatory decisions in Australia. The role of the AAT is "to provide independent merits review of administrative decisions". ${ }^{8}$

The Tribunal reviews a wide range of administrative decisions made by Australian Government ministers, departments and agencies ... The Tribunal aims to provide a review mechanism that is fair, just, economical, informal and quick. ${ }^{8}$

Most of the AAT's work relates to review of decisions made in regard to social security, worker's compensation and taxation; only 12 of 5682 applications lodged before the AAT in the past financial year related to therapeutic goods, and appeals lodged by pharmaceutical companies often took over a year to resolve. ${ }^{9}$ Fighting litigation is expensive and time-consuming for the TGA; it takes resources away from its core roles, and the threat of legal appeal may undermine the capacity for regulators to make decisions solely in the best interests of public health. ${ }^{10,11}$

How well is the AAT equipped to make final judgments concerning the safety and efficacy of medicines? How well does the TG Act support the primary aim of promptly making scientifically sound decisions in the best interests of public health? Under the TG Act, the initial decision for deregistration of a medicine is made by the government on the grounds that safety, quality and efficacy are unacceptable. This can be contested by the manufacturer, who has the right to request the Minister to reconsider the decision; and then, if the manufacturer finds that outcome unsatisfactory, they can apply to the AAT for independent merits review of the decision.

In conducting that review, the AAT is not required to judge safety and efficacy by the usual standards set down for registering therapeutic goods by regulatory agencies worldwide - that is, on evidence of efficacy from clinical trials. ${ }^{12}$ The interim AAT judgment in this case stated:
There is no case law known to the Tribunal that suggests that the words 'safety or efficacy' should be construed otherwise than as ordinary English words, albeit read in the context of the Act as a whole

and refers to the Macquarie and Oxford dictionaries. ${ }^{1}$ Efficacy becomes "ability to bring about the intended result". Evidence on efficacy presented to the AAT included patients' and doctors' opinions, 1998 Australian Drug Evaluation Committee minutes, and a 1984 publication from an industry-sponsored symposium involving reanalysis of small numbers of patients from previously published studies. ${ }^{1}$

Notably, the clinical trial data that would be a requirement for new drugs for which manufacturers are seeking TGA registration were not present in this case. Dextropropoxyphene gained registration through the process of "grandfathering" after the commencement of the TG Act, and the AAT did not compel the production of such data. In contrast, regulators today require that evidence of efficacy comes from clinical trials conducted to established regulatory standards. ${ }^{12}$

The TGA submitted in the 2012 AAT hearing that after the banning of dextropropoxyphene in the UK "there was a significant reduction in the rate of deaths by suicide and no commensurate increase in the number of deaths associated with other analgesics"1,4 (Box). However, the AAT judgment referred to "the straightforward and inescapable mathematical consequences" of these data being that there had been an increase in suicidal poisoning by other drugs. ${ }^{1}$ The AAT made the following comments about the expert witnesses who agreed with the TGA's interpretation of these data:

... it was plain that both witnesses were highly resistant to conceding any point that might possibly be thought to assist the interests of the Applicant. This was particularly noticeable in both cases in respect of the Hawton et al evidence. ${ }^{1}$ [para 25]

The figure in the Box shows the data ${ }^{4}$ referred to in the judgment (the ban was phased in over the 3 years 20052007). The reduction in all drug suicides (362 fewer in 2008 than 2004) was greater than that from fatal poisonings attributed solely to dextropropoxyphene (196 fewer), suggesting that there may also have been a large additional reduction in mixed-drug overdoses. The frequency of other analgesic poisonings did not change significantly over 13 years (the rate varied between 209 and 287, but the linear trend was horizontal [ -0.5 deaths/year] and the 2010 data are equal to the long-term median [257]). Scientific thinking understands that minor year-to-year fluctuations are expected and are simply statistical noise rather than signals.

In another example, the manufacturer ${ }^{7}$ and the AAT [para 44$]^{1}$ have also made much of the fact that there were more deaths recorded in the past decade in New South Wales coronial inquiries from codeine, paracetamol and tramadol than from dextropropoxyphene; however, no attempt was made to put that into perspective by adjusting for the vastly different rates of use.

The TGA has a statutory obligation under the TG Act to protect Australians against risks posed by unsafe, poorquality and low-efficacy pharmaceuticals. In legal terms, 
the TGA administers the TG Act to ensure the quality, safety and efficacy of any therapeutic good supplied or produced in Australia. The TGA is responsible for licensing manufacturers, approving therapeutic products, and regulating such products once they enter the Australian market.

The developments in Australian law, arising from both policy and adjudicative determinations, potentially erode the ability of the TGA to firmly uphold its mandate. For example, the Australian Government's decision to pay compensation rather than fight the civil litigation concerning the TGA's action against Pan Pharmaceuticals has much broader implications for public health, to the extent that the decision could be interpreted as undermining the regulatory authority of the TGA. ${ }^{10}$

The final AAT decision overruled cancellation of DiGesic and Doloxene from the Register of Therapeutic Goods by the TGA but, despite this, summarised the AAT view on the key issues of efficacy and safety in the following statements:

Given that neither Di-Gesic nor Doloxene have been found to have exceptional efficacy and that the Tribunal has found that the risk of accidental overdose is real such that it was common ground between the parties that the amount of DPP contained in a single blister pack of either Doloxene or Di-Gesic, if combined with alcohol, could in a vulnerable patient be sufficient to create a risk of sudden death - the Tribunal has concluded that the safety and efficacy of Di Gesic and Doloxene would be acceptable if, and only if, additional conditions were imposed which provide a high level of assurance that doctors will prescribe the products (a) only if therapeutically justified; (b) only after they have considered any contraindications and any recent changes to the patient's clinical presentation or medical status; and (c) only after they have discussed with their patient the appropriate use of the products and the risks of overdose. ${ }^{7}$ (para 44)

and

... the safety and efficacy of Di-Gesic and Doloxene would be acceptable if, and only if, there were conditions put in place directed at minimising the risk that doctors might prescribe the product if a patient's history indicates that he or she is at risk of intentional self-harm". ${ }^{7}$ (para 45)

The AAT expectation that doctors and patients can comprehensively deal with the consequences of this decision contrasts with clear contemporary evidence that consistent delivery of care according to guidelines does not usually occur in the Australian health system. ${ }^{13}$

This case highlights the need to reconsider whether this appeal process appropriately serves the Australian public interest. Many developing countries around the world regard Australian registration of a therapeutic good as evidence that the drug has passed thorough scientific review. ${ }^{14}$ The current market for dextropropoxyphene is now almost entirely in such countries. When registration can be contrary to TGA advice and based around civil court proceedings rather than scientific interpretation of evidence, the international reputation of Australia's drug regulatory system could be at stake.

\section{Conclusion}

Regulators need to consider legislation and precedents when undertaking regulatory actions on registered drugs, but ultimately this is a finely nuanced expert scientific judgement about evidence of risk and benefit. ${ }^{15}$ Evidence of harmful effects is often of lower quality and might take many years to accumulate. An alternative appeal process such as that used by the US Food and Drug Administration, based around independent expert panels and ombudsmen, might be better for reviewing disputed scientific evidence. ${ }^{16}$ The evidence put forward at appeals should be restricted to that generally accepted by regulatory bodies. The Commonwealth Parliament could also legislate to protect the TGA (and other scientific regulators) from legal challenges against good-faith actions designed to protect public safety; that is, when they are acting in the presence of substantial (but not conclusive) proof of significant harm. Such legislation might have safeguarded the TGA from actions in the Pan litigation; the TGA acted promptly to protect public health after discovery of widespread and serious breaches in manufacturing practice, only for taxpayers to lose over $\$ 122$ million dollars in subsequent court cases. ${ }^{10}$

There was a very long lead time during which there were increasingly strong warnings to prescribers that the riskbenefit ratio of dextropropoxyphene was unfavourable $e^{2,5,6}$ before the TGA finally sought delisting (the last of the world's leading drug regulatory agencies to do so). ${ }^{2}$ We are concerned that the Australian legislative and appeal framework and recent adverse litigation against the TGA contributed to this delay. While acting too early restricts drugs that are potentially still useful in some individuals, late action has often been measured in lives lost (thousands have died worldwide from dextropropoxyphene poisoning, ${ }^{3,4}$ and several deaths have occurred in Australia even as this appeal has unfolded [National Coronial Information System; unpublished data]). The TGA should be empowered to generate further evidence, or take prompt action on the balance of probabilities. ${ }^{17}$ There is only one benefit to the Australian public that could come from this current appeal - it should clearly highlight to our government the urgent need to revise the legal appeal processes that in our view inappropriately burden the TGA when it decides to take action to protect the Australian people.

Competing interests: Nick Buckley was an expert witness at the AAT appeal against the delisting of dextropropoxyphene; he is also a member of the Advisory Committee on the Safety of Medicines and the Chairman of the Editorial Advisory Board of the Australian Medicines Handbook.

Provenance: Not commissioned; externally peer reviewed.

1 Aspen Pharmacare Australia Pty Ltd and Minister for Health and Ageing [2012] AATA 362 (15 June 2012). Last updated Aug 2012. http://www.austlii.edu.au/ au/cases/cth/aat/2012/362.html (accessed Jan 2013).

2 Therapeutic Goods Administration. TGA to cancel four prescription pain-killers from 1 March 2012. TGA, 2 Dec 2011. http://www.tga.gov.au/newsroom/media2011-dextropropoxyphene-111122.htm (accessed Jan 2013).

3 Finkle BS. Self-poisoning with dextropropoxyphene and dextropropoxyphene compounds: the USA experience. Hum Toxicol 1984; 3 Suppl: 115S-134S.

4 Hawton K, Bergen H, Simkin S, et al. Six-year follow-up of impact of coproxamol withdrawal in England and Wales on prescribing and deaths: timeseries study. PLOS Med 2012; 9: el001213.

5 Rossi S, editor. The Australian medicines handbook: AMH. Adelaide: The Australian Medicines Handbook Unit Trust, 2000.

6 Therapeutic Guidelines Expert Writing Group. Therapeutic guidelines: analgesic. Version 4. Melbourne: Therapeutic Guidelines Ltd, 2002. 


\section{For debate}

7 Aspen Pharmacare Australia Pty Ltd and Minister for Health and Ageing [2013] AATA 197 (5 April 2013). Last Updated: 10 Apr 2013. http://www.austlii.edu.au/au/cases/cth/aat/2013/197.html (accessed Apr 2013).

8 Administrative Appeals Tribunal. What we do. http://www.aat.gov.au/AboutTheAAT/IntroductionToTheAAT.htm (accessed Aug 2013).

9 Administrative Appeals Tribunal of Australia. [Database of decisions]. Australasian Legal Information Institute. http://www.austlii.edu.au/au/cases/cth/aat (accessed Jan 2013).

10 Shirlow E, Faunce T. Recent legal developments and the authority of the Australian Therapeutic Goods Administration. J Law Med 2009; 16: 764-769.

11 Hamburg MA. Shattuck lecture. Innovation, regulation, and the FDA. NEngl J Med 2010; 363: 2228-2232.

12 Therapeutic Goods Administration. Note for guidance on good clinical practice (CPMP/ICH//35/95). TGA, 2000. http:// www.tga.gov.au/industry/clinical-trials-note-ichl3595.htm (accessed Jan 2013).

13 Runciman WB, Hunt TD, Hannaford NA, et al. CareTrack: assessing the appropriateness of health care delivery in Australia. Med J Aust 2012; 197: 100-105.

14 Ratanawijitrasin S, Wondemagegnehu E. Effective drug regulation: a multicountry study. World Health Organization, 2002.

15 Committee on Ethical and Scientific Issues in Studying the Safety ofApproved Drugs, Board on Population Health and Public Health Practice, Institute of Medicine. Ethical and scientific issues in studying the safety of approved drugs. Washington, DC: National Academies Press, 2012.

16 US Food and Drug Administration. About FDA. CDER Ombudsman. http://www.fda.gov/AboutFDA/CentersOffices/Officeof MedicalProducts andTobacco/CDER/ContactCDER/CDEROmbudsman (accessed Jan 2013).

17 Hamburg MA. The growing role of epidemiology in drug safety regulation. Epidemiology 2011; 22: 622-624.

\section{Australia's most trusted source of medical information}

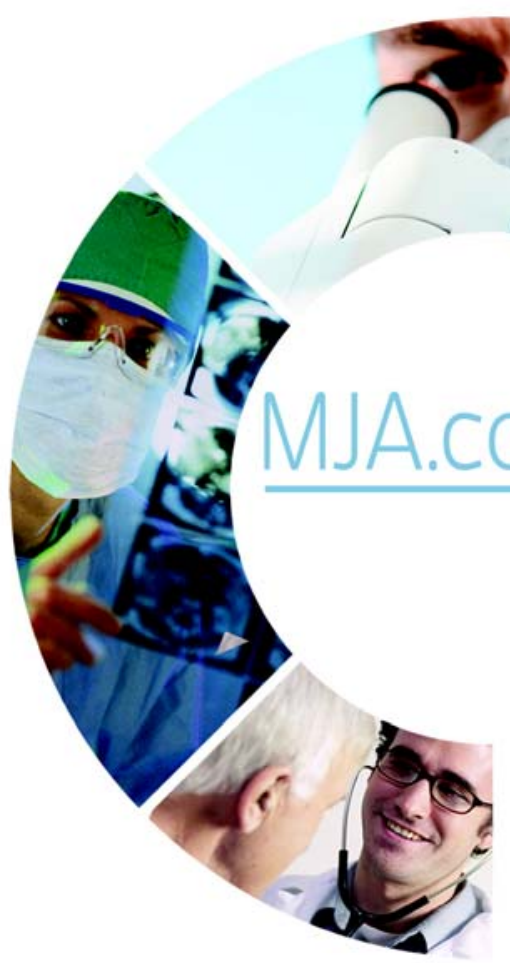

Subscribe today

www.mja.com.au/subscribe

subscriptions@mja.com.au

0295626617
Leading the field in publishing medical research, commentary and clinical material. The MJA is continually expanding its presence in print and online to meet the needs of a modern world.

Read and interact with Australia's leading medical minds, access our archives, and keep up to date with your profession and the wider issues that influence health and health care.

Join the MJA community

Online and Print annual subscriptions available 